\title{
Technical Innovation of LH2/LOX Rocket Engines in China
}

\section{Chengzhi 李成智, ${ }^{1}$ MA Bingtao 马炳涛2}

(Institute for Advanced Studies in Humanities and Social Sciences, Beihang University, Beijing 100191, China)

\begin{abstract}
This paper provides a detailed introduction to and analysis of the course of China's technological innovation in liquid hydrogen/liquid oxygen (LH2/LOX) rocket engines from a historical point of view. It starts with the investigation of LH2/LOX rocket engines by relevant departments of the Chinese Academy of Sciences in the 1960s and their preliminary achievements. Then, the policy decision concerning LH2/LOX engine development, the project approval of the Long March-3 (Chang Zheng-3, CZ-3) rocket, and the process of developing LH2/LOX engines are analyzed in detail, followed by an introduction to and summary of the development situation and technical innovation characteristics of China's LH2/LOX engines as they grew from 4 tons to 8 tons, and finally to 50 tons. Finally, the paper briefly analyzes the innovation experience connected with China's LH2/LOX engines.
\end{abstract}

Keywords: LH2/LOX rocket engines, technological innovation, historical process, China

摘 要: 本文从历史角度较为详细地介绍与分析了中国液氢液氧火箭发动机的技术创新 历程。首先，介绍了中国科学院有关部门 20 世纪 60 年代对氢氧发动机开展的探索以及 取得的初步进展；其次，对氢氧发动机研制的决策以及长征三号火箭立项和氢氧发动机 研制过程进行了详细分析; 再次, 对中国氢氧发动机从 4 吨级到 8 吨级, 再到 50 吨级 几个阶段的发展概况及技术创新特点进行了介绍与总结; 最后，简要分析了中国氢氧发 动机创新的若干经验。

关键词：氢氧火箭发动机，技术创新，历史过程，中国

Received: July 3, 2020. Revised: November 11, 2020.

Projects funded by the National Social Science Fund (19BDJ064). This article was translated into English by Gao Wenrui 高文睿 and copyedited by Charlie Zaharoff.

1 Research interests: Technology and public policy, history of aerospace, aerospace policy, and development strategy. Email: lichengzhi@263.net

2 Research interests: Public management, science and technology management. Email: mabing tao@buaa.edu.cn 


\section{Introduction}

Tn terms of energy and performance, the combination of liquid hydrogen and liquid Loxygen is ideal as a propellant for rocket engines, a conclusion reached as early as the beginning of the twentieth century by Konstantin E. Tsiolkovsky, the Russian space pioneer. Not long after, Robert H. Goddard, the American rocket pioneer, also pointed out that liquid hydrogen and liquid oxygen together formed the most ideal propellant for rockets. However, due to the low boiling point of liquid hydrogen, which makes it difficult to prepare and store, rockets before World War II were mainly fueled by propellants using LOX/alcohol, LOX/gasoline, nitric acid, and hydrazine. Shortly after World War II ended, the United States began to research LH2/LOX rocket engines. On November 14, 1958, General Dynamics won the contract to develop the rocket for the Centaur upper stage using the RL-10 LH2/LOX engine developed by the Pratt \& Whitney company. The engine and the upper stage were first installed in the Kosmos Launch Vehicle in November 1961, and the test was successful. With a vacuum thrust of only 6.8 tons, the engine was widely used in Atlas, Titan, and Saturn I rockets. In view of the success of RL-10, the US began to develop J-1, another LH2/LOX engine with a thrust of 104 tons. Due to the outstanding performance of this type of engine, the Soviet Union, Europe, Japan, and China all started to develop it. In China, the development history of LH2/LOX engines is significant for further exploration and innovation.

\section{Early explorations by the Chinese Academy of Sciences}

Due to the high energy, stable combustion, and high thrust of the LH2/LOX engine and the nontoxicity of its propellant and combustion products, the Chinese Academy of Sciences (CAS) started research in this area fairly early. In 1958, when the CAS formulated a plan for the development of artificial satellites, it was proposed that the Fifth Academy of the Ministry of Defense should develop strategic missiles with conventional propellants, while the CAS should take the lead in investigating highenergy propellants and engines. In 1959, the Institute of Mechanics of the CAS (IMCAS) established an experimental base for high-energy propellants and rocket engines in the suburbs of Beijing, making possible the experiments on "combustion and heat transfer of LH2/LOX engines” (氢氧发动机的燃烧及传热问题). Under the guidance of Qian Xuesen 钱学森 and Lin Hongsun 林鸿䔉, more than two years were spent on an exploratory study of the overall scheme of the LH2/LOX engine, experimental research on small engines, and the establishment of the heat transfer experimental system of LOX under supercritical pressure and the combustion test system of the LH2/LOX rocket engine. In accordance with the arrangement of the Commission of Science, 
Technology and Industry for National Defense (COSTIND), the appraisal report was completed in April 1966, and all the research results and technical data were submitted to the Fifth Research Institute (which has since been reorganized as the Seventh Ministry of Machine Building Industry) (Fan 1999, 103-127).

As the power system of launch vehicles, the LH2/LOX rocket engine has its unique advantages: high energy and a specific impulse of up to 420 seconds, which are conducive to a great increase in the payload capacity. The LH2/LOX rocket engine exhibits high performance and outstanding merits, but it also poses great technical difficulties. In summary, in addition to the problems of liquid-hydrogen preparation and cryogenic storage, early researchers still faced many technical hurdles: long-life LH2/LOX thrust chamber technology; structural resonance suppression technology; high-performance nozzle extension technology; flexible rotor stability technology; cryogenic, high-speed, heavy-duty turbine and bearing technology; cryogenic, lowleakage dynamic sealing technology; high cavitation-resistance inducer technology; revolving shaft rotary dynamic sealing technology for cryogenic ball valves; highpressure pipeline compensator technology; large liquid hydrogen tank and thermal insulation technology; and so forth. These technical difficulties were closely linked with new materials, high-level processing technology, precision testing technology, and ground test technology, which had to be fully equipped with basic industrial support. Therefore, it was extremely difficult for China to develop such engines at that time (Zheng et al. 2014). In the early 1960s, the US was the only country able to successfully develop the engine. In China, in the absence of all relevant information, scientists from the Thirteenth Laboratory of the IMCAS (later changed to Huairou Branch), under the direct leadership of Qian Xuesen and the organization of Lin Hongsun, spent six to seven years in the preliminary research of LH2/LOX rocket engines.

A team led by Lin Hongsun studied the overall performance of LH2/LOX engines with 15 tons of thrust and 100 tons of thrust, and a research report was put forward. The analysis of the characteristics of the thrust chamber suggested that liquid hydrogen as a cooling medium was quite different from general liquid propellant. A calculation of the thermophysical properties and variation curve of hydrogen in a critical state indicated that the density of hydrogen changed constantly. Therefore, a design scheme was proposed in which a variable cross-section tube served as the regenerative cooling channel for the hydrogen medium. Analysis and research also led to the decision that, after passing through the cooling inner wall, the liquid hydrogen should be in the gas state and the oxygen in the liquid state when entering the thrust chamber. An optimization scheme with a ring injector was thus proposed.

When it comes to the combustion process of the LH2/LOX thrust chamber, Lin Hongsun and others put forward a combustion model with liquid oxygen droplet evaporation controlling the combustion rate, which provided an accurate description of 
the working process of the LH2/LOX engine's combustion chamber, and an important basis for the design of the combustion chamber was provided through calculations and analysis. In addition, Lin Hongsun did an in-depth study of combustion oscillation and theoretically pointed out a method to solve the problem of unstable combustion, which aroused great interest in the theoretical community and engine design departments in China. The Thirteenth Laboratory of the IMCAS carried out the research on turbulent heat transfer of liquid hydrogen and liquid oxygen under supercritical pressure and proposed a heat transfer model. At the same time, an experimental system of liquid oxygen heat transfer under supercritical pressure was established to provide data for the design of heat transfer and the calculation of cooling inner wall resistance.

During the four years from 1960 to 1964, the Huairou Branch of the IMCAS successively established test beds for combustion chambers with nitric acid/aniline, gas hydrogen/liquid oxygen, and liquid hydrogen/liquid oxygen, and set up a heat transfer laboratory. A large amount of valuable experimental data was obtained. Important achievements had been made in experimental technology and measurement technology of nitric acid/aniline combustion chambers, and further experimental research on combustion oscillation was planned. In addition, the branch carried out several performance tests for combustion chambers with gaseous hydrogen and liquid oxygen as propellants and with a thrust of $200 \mathrm{~kg}$. The longest steady run time was more than 400 seconds. The data obtained from the tests of combustion chamber performance were quite consistent with theoretical values, which provided an important reference for the design of thrust chambers. At the same time, a series of technical problems related, for example, to ignition starting, injector design, pressure regulation, mixing ratio control, and testing technology were solved. On November 24, 1964, under the command of Lin Hongsun, China's first formal ground test of a $500 \mathrm{~kg}$ thrust rocket engine using LH2/LOX as propellant was successfully ignited, and the test-firing lasted for more than 20 seconds, marking a major technological breakthrough in the development of this high-energy rocket engine, particularly as it related to the mastery of cryogenic technology (Hong 2006). The above achievements served as a critical starting point and laid an important foundation for the development of the third-stage LH2/LOX engine for the Long March-3 (Chang Zheng-3, CZ-3) launch vehicle (Bai 2012).

\section{Pre-research of the Seventh Ministry of Machine Building Industry}

According to the decision of the COSTIND, in 1966, the IMCAS made a serious appraisal and summary of the research on LH2/LOX engines and handed the technical data and achievement reports over to the First Academy of the Seventh Ministry of Machine Building Industry (hereinafter referred to as the Seventh 
Ministry) (Zhang 2006).

It was in March 1965 that the First Academy of the Seventh Ministry started its research on LH2/LOX rocket engines. With the advocacy of the space expert Ren Xinmin 任新民, the Institute of Liquid Rocket Engines set up a research team for the exploration and pre-research of LH2/LOX engines. At that time, research on the engine abroad had just entered the practical stage. Due to reasons of confidentiality, however, the reports and information concerned were very rarely available. As a result, the main tasks for China's research team included investigation, data collection, and exploratory work. After the successful launch of the satellite Dong Fang Hong-1 (DFH-1), on June 13, 1970, the COSTIND urged the Seventh Ministry to promptly organize a team to carry out preliminary research work on LH2/LOX engines. Accordingly, Lu Qingjun 卢庆骏, vice president of the First Academy of the Seventh Ministry, devoted himself to organizing the Institute of Liquid Rocket Engines (the Eleventh Institute) and the 101 Station for pre-research on LH2/LOX engines, and engaged in formulating a plan to rebuild the No. 2 test bed. A preresearch plan was soon worked out, and a special research lab was set up. On January 16, 1971, a pressure-fed hot-fire test of an LH2/LOX thrust chamber was carried out. The ignition was successful, and the thrust was $7.84 \mathrm{kN}$. On September 23 of the same year, the first $39 \mathrm{kN}$ hot test run of LH2/LOX extrusion was carried out in the 101 Station, also with successful results. In November 1972, cryogenic vacuum vessels $\left(6.5 \mathrm{~m}^{3}\right.$ and $\left.30 \mathrm{~m}^{3}\right)$ were successfully developed by the 101 Station, laying a foundation for later LH2/LOX engine tests. At the beginning of 1973, the First Academy proposed in a model plan that the development of LH2/LOX engines should be vigorously promoted. Later, it put forward the plan of adding LH2/LOX engines on intercontinental ballistic missiles to form a three-stage launch vehicle (that is, CZ-3). However, technical challenges in the development led to a lasting debate on whether the launch vehicle for the communication satellite Dong Fang Hong-2 (DFH2) should adopt the conventional propellants or use the LH2/LOX engine for the third stage (Xiao 1999, 172). It was not until 1979, when the LH2/LOX engine passed the long hot-fire tests repeatedly, that it was finally decided to adopt an LH2/LOX engine stage in the launch vehicle for communication satellites (Zhang 1986, 217).

During the exploration of LH2/LOX engines, the Institute of Liquid Rocket Engines of the First Academy built an experimental combustion chamber with hundreds of kilograms of thrust and a single-tube combustion chamber for LH2/LOX engines with tons of thrust. Several tests were conducted with desirable results, which inspired the confidence of scientists and engineers in the development of LH2/LOX engines.

A major problem during the pre-research was the development of turbopumps, which, similar to all rocket engines, was a quite essential technology. But lacking 
even the minimum equipment for a turbopump test at that time, the researchers decided to build a test bed on their own. They built an ultra-low-temperature highspeed gear test bed in a short time by modifying the existing equipment, and solved the problem of ultra-low-temperature gear lubrication with the assistance of the Changchun Institute of Applied Chemistry, CAS. A concern for the researchers at the beginning was the development of a hydrogen turbopump, which, after the successful design of the liquid hydrogen turbopump, was followed by a new problem in the turbopump testing, primarily concerning how to drive the turbopump for the test. To solve the problem, researchers went through hardships with the humble supplies available to them, and finally built a "LH2 semi-system test bed," which not only enabled the measurement of head-flow characteristics of the pump but also examined the insulation and pre-cooling of the liquid hydrogen turbopump and its coordination with the valve of the turbopump. In March and April 1974, the first liquid hydrogen turbopump was tested successfully on the LH2 semi-system test bed, marking a breakthrough in the pre-research of LH2/LOX engines (Zhu and Zhu 1999, 428).

\section{Decision on the CZ-3 rocket scheme}

As early as 1970, the COSTIND entrusted the Seventh Ministry with a seminar on the "three satellites and one ship" (三星一船) scheme. It was determined that the launch vehicle for the communication satellite of DFH-2 should be Dong Feng-5 (DF-5) combined with a conventional third stage, or that the satellite should be launched by the Dong Feng-6 global missile under development.

To improve the launching capacity, the First Department, together with the Eleventh Institute of the China Academy of Launch Vehicle Technology (CALT), formerly the First Academy, and other relevant organizations, proposed to add an LH2/LOX third stage on the basis of DF-5. Besides that, there was also the debate over whether the third-stage engine should be started up once or twice. The so-called "two start-ups" meant that the third-stage engine could be ignited twice, with an unpowered ascent between the first and the second ignition. This could save the energy of the rocket and improve the launching capacity and the guidance precision. However, it brought about many technical problems, such as the ignition of the engine in weightlessness, and the control of the rocket attitude during the unpowered ascent $(\mathrm{Li}$ 2006, 474-477; Ли [Li] 2014, 98-110).

According to the report submitted by the General Design Department of the CALT in June 1973, the capacity of the launch vehicle to launch a communications satellite would be only $275 \mathrm{~kg}$ if a third stage with conventional propellant was added to DF-5, while the rocket with an LH2/LOX third stage could launch a communication satellite 
of $550 \mathrm{~kg}$. The difference was drastic. At the planning meeting held in Tangshan from August 6 to 13 of that year, the Seventh Ministry decided to add a third stage with conventional propellant to DF-5 as the launch vehicle for the communication satellites. The third stage consisted of two conventional propellant engines in parallel, which could be started up twice.

After the plan was made by the COSTIND and the Seventh Ministry for the development of communication satellites, the Seventh Ministry held a " 748 " conference in August 1974 to further discuss the launch vehicle program. There was no dispute that DF-5 would be used as the first and second stages of the launch vehicle, but a debate occurred among scientists over whether a new LH2/LOX engine or one with conventional storable propellant should be used in the third-stage power system. For some, given the LH2/LOX engine's lack of development and the weak foundation of cryogenic technology in China, the ability to develop a new high-performance engine in a short time would be impeded by difficulties not only in key technologies but also in materials, equipment, techniques, and so forth. For others, in spite of China's rich experience in the development of conventional propellant engines as well as the few key technologies involved and its shorter development period, the LH2/LOX engine had greater advantages in terms of performance and prospects. For the long-term interests of China's space industry, the development of LH2/LOX engines was a farreaching move, and a breakthrough was needed (Zhu and Zhu 1999, 429). Ren Xinmin strongly advocated the development of LH2/LOX engines. "Each of the two options is characterized by its respective advantages and disadvantages," he said. "For the LH2/LOX scheme, despite the large number of key technologies and other difficulties, such as the longer development period and heavy workload involved, it provides high launching capacity, which is necessary for launching high-orbit satellites. And from the perspective of long-term development, we will move on to LH2/LOX engines sooner or later" (Xiao 1999, 172). ${ }^{3}$ He also analyzed the facilities, equipment, and researchers of China's space industry. In particular, based on the successful results of the LH2/LOX pressure-fed hot-fire test and the semi-system hydrogen turbopump test, he repeatedly laid out the reasons to expect a promising breakthrough of LH2/LOX engines, which remained a big technical challenge.

At the " 748 " conference, experts supporting each scheme expressed their opinions, and no one was persuaded. The conference was concluded with the decision that LH2/LOX propellant and conventional propellant should both be adopted for the third-stage engine of the launch vehicle (Xiao 1999, 175). At the communication satellite engineering demonstration meeting held by the COSTIND in September 1974, it was

3 “两种方案各有特点, 各有利弊。氢氧方案尽管关键技术多, 难度比较大, 研制周期长, 工作量 大。但采用氢氧方案能提供高运载能力, 这正是发射高轨道卫星所必须的。而且从长远发展的角度 考虑, 氢氧发动机这个台阶迟早是要上的。” 
finally decided that both schemes should be carried out simultaneously. On November 21, the DF-5 with a conventional third stage was named Long March-2A (Chang Zheng-2A, CZ-2A) by the Seventh Ministry, and DF-5 with an LH2/LOX third stage was named Long March-2B (Chang Zheng-2B, CZ-2B). The two schemes had their advantages and disadvantages respectively, and the conventional scheme was considered slightly superior in terms of the naming order.

Of course, the choice between the cryogenic scheme and the conventional scheme depended not only on the technological advancement and hardships but also on another important factor-time. At that moment, it was also advocated that the top priority be given to the conventional third-stage rocket in consideration of the development period, without giving up the LH2/LOX engine.

The pre-research on the LH2/LOX engine was carried out in full swing, and it went smoothly. The combustion chamber test, semi-system test, valve test, and four engine tests were completed. Therefore, at the " 331 " 4 general project demonstration meeting held by the COSTIND in February 1976, it was decided that the LH2/LOX engine scheme be adopted for the third stage of the launch vehicle. At the "331" meeting from July 15 to August 12, 1976, the COSTIND further clarified that the first and second stages of the launch vehicle would be based on DF-5 with slight improvements, and that the third-stage power system would use the newly developed LH2/LOX engine, which could be restarted in such a way that a $1300-1500 \mathrm{~kg}$ communication satellite could be launched into the earth's synchronous transfer orbit. This would not only meet the needs of that time, but was also a favorable choice in the long-term development of spaceflight. The conventional propellant scheme for the third stage was taken as a backup. The whole plan was strategic and greatly significant.

On December 28, 1977, the above two types of launch vehicles were renamed by the Seventh Ministry: CZ-2B was given the name Chang Zheng-3 (Code: CZ-3) and CZ-2A the name New Chang Zheng-3 (Code: CZ-3A). But only a month later, an explosion in the hot-fire test of the LH2/LOX engine again caused concerns about safety (Zhu and Zhu 1999, 430). At the working conference on satellite communication engineering held in Shanghai in the spring of 1978, the conventional propellant scheme was determined to take priority, and the LH2/LOX engine was deemed an alternative.

On learning the news after coming back to China from Japan, Ren Xinmin talked to Ma Jie 马捷, deputy director at the COSTIND. "Both conventional and LH2/LOX engines are capable of launching communication satellites, but the latter is a lot more advanced," he said. "With the continuous development of space technology, the LH2/LOX engine is a must, and it is better to develop it sooner rather than later. Besides, the prerequisites for the development are all ready and we are certainly able to

4 In March 1975, the Central Committee of the Communist Party of China officially named China's communications satellite project "The 331 Project." 
do it. There is no need to cling to imperfections and hold back!"5 As a senior expert, Ren Xinmin propounded viewpoints that reflected the situation and trend of liquid rocket engines in other countries, and took into account the short-term needs and longterm development of China's rocket engine technology, which made his arguments highly convincing. Superior officials of the COSTIND studied the situation and decided that the governmental documents should be coded with the word "第" (No.) instead of “另” (Alternative No.), meaning that the LH2/LOX development was considered the primary scheme, while the conventional engine scheme became the backup. A change of one single word determined the fate of the LH2/LOX engine. The story of Ren Xinmin asking for instructions about the LH2/LOX engine became well known in China's space community (Xiao 1999, 176-177).

\section{Successful installation test of LH2/LOX engines}

After the "748" conference, the pre-research of LH2/LOX engines was carried out rapidly. By January 1975, the whole-engine hot-fire test of the first LH2/LOX engine in China had been successfully conducted, which laid a good foundation for the development of the formal engine model. On March 31, 1975, Mao Zedong gave approval to the plan to develop communication satellites, which was listed as a key project of the state at that time.

Due to the great progress made in the preliminary research of the LH2/LOX engine, in August 1976, the Seventh Ministry made an official decision to use it as the third-stage power system of the launch vehicle for communication satellites. From that point on, the research and development of the LH2/LOX engine model was carried out in accordance with scientific research procedures. The research was organized and instructed by Ren Xinmin, Zhang Lianfu 张镰斧 (president of the First Academy of the Seventh Ministry), and Lu Qingjun (vice president of the First Academy), and was directly led by engine experts, such as Liu Chuanru 刘传儒 and Wang Zhiren 王之任 (Zhu and Zhu 1999, 429).

As the pre-research continued, although some complex technologies concerning cryogenics had been grasped, there were still other scientific laws remaining to be mastered, for which great efforts were made and sometimes lives were risked. In January 1978, a serious explosion occurred during an experiment. In March of the same year, when debugging a hydrogen-turbopump test bed, another fire broke out, and the flame soared more than ten meters high. Lessons were drawn from the accidents, and knowledge of safe discharge and explosion-proof methods of liquid

5 “常规发动机和氢氧发动机都是可以发射通信卫星的, 但氢氧发动机要先进得多。随着航天技术 的不断发展, 氢氧发动机迟早是要搞出来的。既然非搞不可, 晚搞不如早搞, 何况我们有条件有能 力搞出来, 而且也一定能搞出来的。何必抱残守缺, 裹足不前呢! ” 
hydrogen and gas hydrogen were gradually mastered, preventing the occurrence of similar accidents in later tests (Zhu and Zhu 1999, 430).

During the development of LH2/LOX engines, a series of technical problems were solved.

The first was the turbopump. In April 1980, a long hot-fire test of the engine lasted for over a thousand seconds. In the hot-fire test, the turbo-shaft was seriously damaged due to overheating caused by the high speed of the turbine. In order to analyze the faults and eliminate them, researchers endeavored to make two improvements: one in the shaft design and the other in the test conditions. Many measures were taken, and a new shaft was developed with the help of the Luoyang Bearing Research Institute. Over more than half a year, under the direct leadership of Ren Xinmin and Lu Qingjun, scientific researchers made continuous improvements by way of conducting repeated experiments, changing materials, and increasing the precooling flow rate, and finally developed a new turbo-shaft, thus solving the problem.

Cryogenic sealing was the second problem impeding development. As static seals, dynamic seals, and high-temperature gas seals were all required, different measures were taken to attain them. For the thousands of engine connectors on the engine, they tried as much as possible to use welding instead of spherical seals. For those that could not be welded, the structure, material, and surface finish of the sealing were strictly specified, and the torque for the sealing elements was quantified. And on the six dynamic seals on the LH2/LOX pump, problems such as serious friction and wear, cracks on the chrome-plated surface of the moving ring, sealing-off on the sealing capsule, and dynamic instability were encountered. The reliability of dynamic seals was greatly improved after effective modifications, and their sufficiency was verified by the hot-fire test.

Since the general metal " $\mathrm{O}$ " ring could not compensate for the gap caused by the large temperature difference, the hot-fire test failed many times due to the fire leakage at the joint of turbine and gas generator. In order to discover the cause of the fire leakage as soon as possible, some of the researchers sat by the video recorder, watching the hot-fire test frame by frame, looking for where the fire leakage happened; some worked with workers on the decomposition and sealing test of the test models; some sat at the meeting table discussing the factors that caused the failure and the remedial measures to be taken. After several months of hard work, according to the characteristics of the LH2/LOX engine, namely that it was assembled at room temperature but worked at ultra-low temperature, researchers put forward a comprehensive method to prevent leakage and adopted a graphite expansion gasket. Another test showed that these measures were effective, and the fire leakage was eliminated completely (Zhang 1986, 218). 
The problem of the cryogenic turbo-shaft was solved in April 1980. In 1982, as great progress was being made in engine development, another major technical problem turned up - the subsynchronous resonance of a turbopump. Because of the randomness of its occurrence, the engine often worked normally; but in other cases, the engine would be seriously damaged. Researchers once mistook it for an accident. But after data analysis of the faults, scientists and technicians came to believe that it was caused by the inherent vibration characteristics of the engine, and that the resonance happened naturally when the turbo-shaft reached its critical frequency at a specific revolving speed. At the same time, the Institute of Structure and Environmental Engineering also confirmed after theoretical analysis that it was the phenomenon of subsynchronous resonance, and pointed out that the reliability of the engine could not be guaranteed if the problem was left unsolved.

To this end, under the direct leadership of the CALT, a research team was set up, which mainly consisted of scientists from the Institute of Liquid Rocket Engines and the Institute of Structure and Environmental Engineering. On the basis of further hotfire tests and theoretical analysis, the team carried out a series of vibration reduction tests and adopted a variety of measures. After more than half a year of analysis, calculation, and testing, various methods were adopted, including moving the turboshaft forward, changing the shaft seat to elastic support and clearance adjustment (which reduced the critical revolving speed of the turbo-shaft), and increasing the external damping while reducing the internal damping, which together effectively eliminated the subsynchronous resonance. This was an important turning point for the successful development of LH2/LOX engines (Zhu and Zhu 1999, 432). At the end of 1982, the problem of subsynchronous resonance of LH2/LOX engines was solved thoroughly, as demonstrated by three successful 1400-second long hot-fire tests.

In July 1982, during the simplified hot-fire test of the third-stage LH2/LOX engine of CZ-3, "backfire" occurred three times, which meant the flame shrank back shortly after a long flame spat. The cycle of spitfire-backfire-spitfire repeated three times, each lasting for about five seconds, and the shortest for about one second. Generally speaking, it was observed more in the first start-up than in the second. Despite the completion of the hot-fire test as expected, the flameout caused by backfire or an excessive interfering force during stage separation could lead to flight instability of the rocket. Accordingly, measures were taken, including increasing the flow rate of the starting hydrogen, increasing the starting power of the turbopump, adjusting the starting procedure of the engine, and improving the quality of the liquid hydrogen before entering the pump. A supplementary ignition test was carried out on the simplified test bed, and the structure was modified based on the test results. According to a number of ignition tests, backfire was no longer observed. On May 25, 
1983, after the first full-system hot-fire test of the third-stage LH2/LOX engine, it was confirmed that the phenomenon of "backfire" had been eliminated completely. And indeed, it never happened again.

While continuously improving the LH2/LOX engine, a large number of technical achievements were made in design, production, testing, measurement, materials, and so on. With the development of high-speed LH2/LOX turbopumps and cryogenic highspeed shafts, and with the mastery of cryogenic sealing and dry-film gear lubrication, the high/low pressure swing hose was successfully developed, and the overall structure layout was produced correspondingly, adopting the scheme of swinging after pump; the thrust chamber was designed with a concentric-ring gap injector; the electric gas valve, capable of working at low temperature, was developed after the mastery of cryogenic automatic devices and sealing technology; and the technology of starting thrust chambers without precooling was mastered. In terms of materials, a laminated stainless steel transpiration panel was adopted to avoid temperature deformation of the injector at the head of the thrust chamber; metal materials with excellent cryogenic performance were used for the thrust chamber; materials for cryogenic seal structure, cryogenic static seal materials, and materials for static seal under high pressure at high/low temperatures were developed. These technologies laid a solid foundation for the development of the new LH2/LOX engine, which was codenamed "YF-73" (Figure 1) (Zhang 1986, 220; Zhang 2013).

On January 29, 1984, when China's first experimental communication satellite was launched by CZ-3, the test was not entirely successful, due to the abnormal operation of the third-stage LH2/LOX engine after the second start-up.

In order to find out the causes of the abnormality, scientists and technicians began devoting themselves to the fault analysis on the eve of the Spring Festival. At the successive analysis meetings, based on the interpretation, calculation, and analysis of telemetry data, a

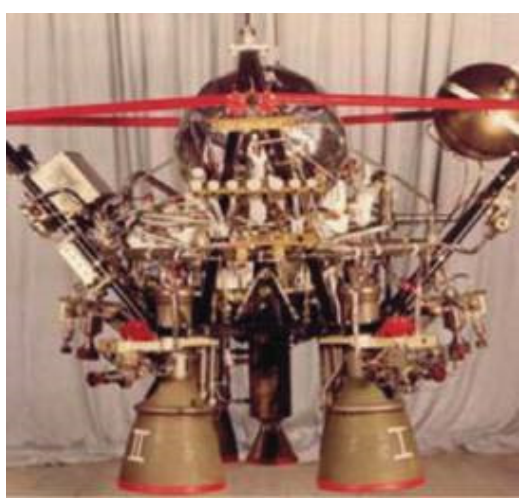

Figure 1: The YF-73 LH2/LOX engine (Zhang 2013, 1). possible failure mode was put forward, and possible improvement measures were proposed accordingly after repeated demonstration. Researchers of design, production, and testing were called on immediately for implementation (Wang 1999, 534). Due to the urgency of the task, in the course of just a few days, researchers worked around the clock on program discussion, design modification, parts processing, and test preparation. In order to ensure an early implementation of the second launch test, the CALT installed a new 
engine in only ten days.

After the laboratory tests were completed, a series of hot-fire tests and other related tests were carried out with the help of 101 Station. The first hot-fire test of the YF-73 engine was carried out successfully on February 20,1984. After that, many tests were carried out that fulfilled expectations, proving that the improved scheme was feasible. In order to speed up the progress and ensure another launch by the middle of April, while preparing for the long reliability hot-fire test, components for the modified engine arrived at the Xichang Satellite Launch Center on March 22. On March 27, the first long reliability hot-fire test of the improved YF-73 was carried out, and the test was successful (Wang 1999, 536).

At 19:20 on April 8, 1984, the CZ-3 launch vehicle was launched again with the DFH-2 experimental communication satellite on top at the Xichang Satellite Launch Center. This time, the two start-ups of the third-stage LH2/LOX engine functioned normally. DFH-2 was finally sent to the synchronous transfer orbit, meaning YF-73, China's first practical LH2/LOX rocket engine, finally succeeded after eight years of development.

\section{New breakthrough in LH2/LOX engine technology}

YF-73, the LH2/LOX engine used in the third stage of CZ-3, provided a vacuum thrust of only 4 tons; its performance was less than desirable. In order to enhance the performance of the launch vehicle, the Academy of Aerospace Propulsion Technology (AAPT) of the China Aerospace Science and Technology Corporation (CASC) made continuous improvements on the engine, especially the vacuum thrust. The AAPT took the lead in the research on the YF-75 LH2/LOX engine for CZ-3A series rockets (Figure 2). Project demonstration of the engine began in 1986, and the first full-system hot-fire test was carried out in 1989 (Wang 1993). The engine was designed as an open-type re-circulating power system-based gas generator with two shafts and two turbopumps in pneumatic series. The scheme of pneumatic series with double turbopumps overcame the difficulty in gear transmission with high power, which was conducive to the operation of both hydrogen and oxygen turbopumps under their respective optimal working conditions. The general assembly structure of the engine was symmetrically arranged, which was more reasonable for nozzle swing. In the meantime, the scheme increased the technical difficulty of engine system development, for instance concerning the control method, the design of gas flow channels between two turbines, and the matching of output power between a supersonic hydrogen turbine and a subsonic oxygen turbine, which caused additional complexity for operation control. To give consideration to the performance and reliability of the engine, in addition to the meticulous design and processing, a 
detailed analysis was also made of the inlet parameters of the two turbines, the flow coefficient of the nozzle, the expansion pressure ratio, the turbine efficiency, the split ratio of the gas flow, the pressure loss of the gas passage between the two turbines, and the mutual interference between the two turbines' parameters. With this, the turbopump experiment was completed (Yuan 1998).

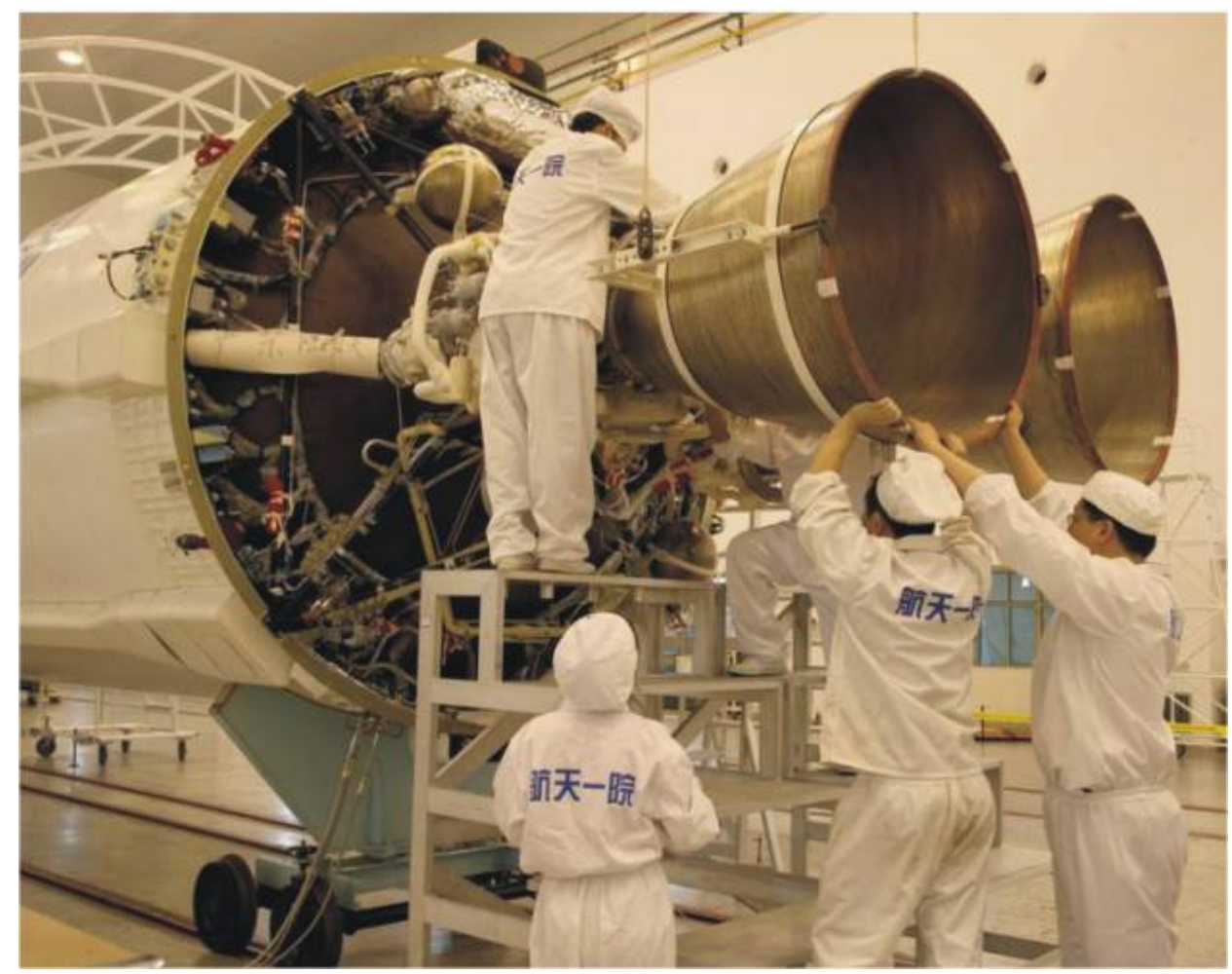

Figure 2: The installation of big nozzles for the YF-75 LH2/LOX engine (CASC 2010).

The YF-75 was also characterized by two start-ups at high altitude. The failure rate of starting a rocket engine, especially the second start-up, was quite high, which was why great importance was attached to the problem both at home and abroad as the key to the engine development. The simplicity and reliability of the system depended on the selection of start-up energy for turbopumps. Gunpowder was more widely used as the start-up energy for storable liquid propellant engines, compared with LH2/LOX engines. The European Space Agency (ESA)'s third-stage HM-7 of the Ariane-1 rocket was one of the few LH2/LOX engines using gunpowder as its starting energy. HM-7 needed only one start-up, while the third stage of the improved CZ-3A launch vehicle required two, which undoubtedly increased the difficulties of development. The third stage of CZ-3A used cryogenic slow-burning gunpowder as its start-up energy, the first to do so in the world at that time (Yuan 1998). For YF-75, the gunpowder formula was 
expected to ensure the compatibility of the combustion products with hydrogen and oxygen gas; because it has less carbon deposition, there is no high temperature when the gunpowder gas ignites the hydrogen and oxygen generator. Given the characteristics of the start-up process of the LH2/LOX engine, the gunpowder was required to keep a low burning rate and be insensitive to the ambient temperature, so that the gunpowder starter could maintain a longer normal working time. During the several combined thermal tests of the gunpowder starter and generator, key technical progress was made, such as the preliminary confirmation of the start-up working procedure of the auxiliary system, the time difference between liquid hydrogen and liquid oxygen entering the generator, and the timing of the successive ignitions. The helium purge parameters required to prevent the gunpowder gas from flowing back into the oxygen subsystem were obtained, which verified that the gunpowder gas also supported the ignition of the hydrogen and oxygen generator.

In order to improve the load capacity of CZ-3A, the YF-75 power system was equipped with a propellant utilization system. Considering the structural complexity, component weight, system parameters, and reliability of the regulating valve, it was finally decided to adopt bypass shunt step regulation in parallel with the main cavitation of liquid oxygen. The scheme measured the difference between the liquid level and the set value in the tank of the rocket in real time. The liquid level sensor gave the signal for the electric bridge and the computer to control the propellant of the engine, which, with the help of the regulating valve, could run under three mixing ratio conditions to ensure the two components of the propellant were exhausted the same time.

The YF-75 thrust chamber adopted copper zirconium alloy for its milling groove inner wall and electroforming nickel for the outer wall, which greatly improved the cooling effect. The side cooling method usually used in the injector was cancelled, which improved the combustion performance. The nozzle extension part was a detachable structure separated from the chamber body. The total area ratio of the nozzle was 80:1. The extension part was a spiral tube bundle, with the advantages of lightness, high strength, and stiffness. A total of 248 tubes with trapezoidal crosssections were bent into a spiral shape and arranged to form a nozzle, and adjacent tubes were connected by hydrogen arc welding to the outer wall. The design of the thrust chamber and the nozzle, together with the scheme of series connection of double turbines, simplified the overall structure of the engine and reduced the weight, thus improving the stiffness and reliability (Wang 1993).

During the development of the YF-75, a lot of hot-fire tests were made and added up to tens of thousands of seconds. The reliable working time of a single engine without repair was 1500 seconds, which was three times longer than its working life. By January 1993, the engine had been tested for 22,065 seconds and started up sixty-seven 
times, with no fault ever found in the period six times its working time (Editorial Committee 1996, 100). From January to April of that year, a record was set when three successive hot-fire tests were completed with a third-stage engine standing on the test bed. The replacement of hydrogen pump and oxygen pump was also carried out at the test bed. The engine design and the test decision saved more than one year's worth of development and saved a large amount of development funds (Long and Nan 2007). The development process witnessed the breakthrough of many technical problems, such as the seal structure of the end of hydrogen LH2/LOX turbopumps and the processing process of spiral tube-bundle nozzles. The structural reliability of the engine reached 0.97 on the first flight. Its vacuum thrust was 8 tons $(78.48 \mathrm{kN})$ (Long 2007, 122), nearly double that of the YF-73, which was 4.5 tons, and the specific impulse was 440 seconds, a new step in technology. On February 8, 1994, the first test-launch of the CZ3A launch vehicle was completed successfully, marking the maturity of the YF-75 LH2/LOX engine and its advancement among other foreign engines (Li 2019). By the end of the twentieth century and the beginning of the twenty-first, the new series of Chang Zheng-3 rocket (CZ-3A, CZ-3B, CZ-3C) had become an important tool for China to launch various application satellites and the Chang'e lunar probe. By April 2020, it had succeeded in 114 launches, ranking among the world's most famous launch vehicles (Jia and Jin 2019).

From YF-73 to YF-75, China's LH2/LOX engines went through a complete technical developing process, and were competent for the upper stage of medium load capacity rocket. However, their performance was still low, with a huge gap in thrust compared with the United States and Europe. Therefore, in line with the principle of "engine first," China started the technical pre-research on the high-thrust LH2/LOX engine in the 1990s. In January 2002, the project approval was given to YF-77, a 50-ton high-thrust LH2/LOX rocket engine (Qiu 2016). The engine, which was composed of two standalone thrust chambers in parallel through the frame, still used a gas generator cycle, pump pressure supply system, and ground start-up. The ground thrust of a single engine was 52 tons $(510 \mathrm{kN})$; the vacuum thrust was 72 tons $(700 \mathrm{kN})$; and the vacuum specific impulse was 438 seconds (Long 2007, 174; Zhang et al. 2007). After the official establishment of the project, the engine successfully passed the extrusion test of the gas generator and the test of the turbopump system. Then, tests and assessments were carried out on the whole engine system. After two ignition tests, the first 50-second short hot-fire test of the whole system went successfully on September 17, 2004, and the reliability appraisal and sampling acceptance test were completed on the same day (Wang, Zheng, and Qiao 2013). On August 3, 2006, a 500-second long hot-fire test was completed for the first time. In 2009, the sample development of YF-77 began. On June 16, 2012, a 520-second long hot-fire test was carried out, and the technical status of the engine of Chang Zheng-5 (CZ-5) was determined for its first flight (Figure 3). 


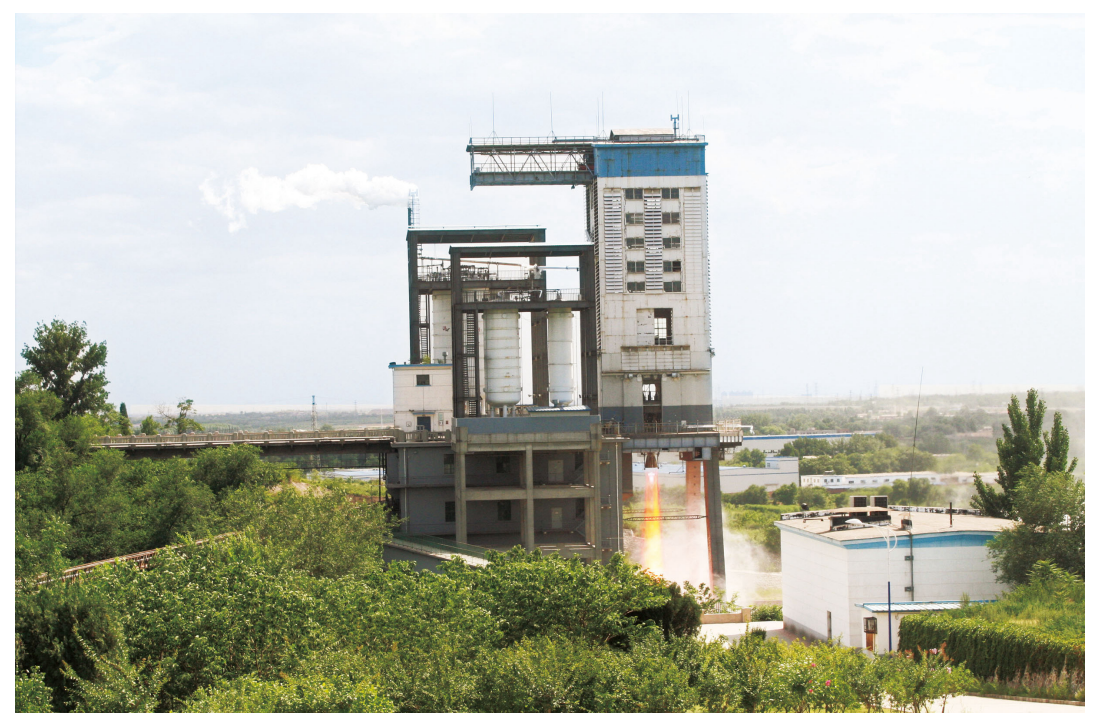

Figure 3: The ground test of the YF-77 LH2/LOX engine (Chen and Zhao 2020).

While the control system of YF-77 was shared by both thrust chambers, each single thrust chamber had five subsystems, including a propellant supply system, gas generator, ignition and start-up system, gas supply system for pressurization and servomechanism, and telemetry system (Figure 4). The single thrust chamber

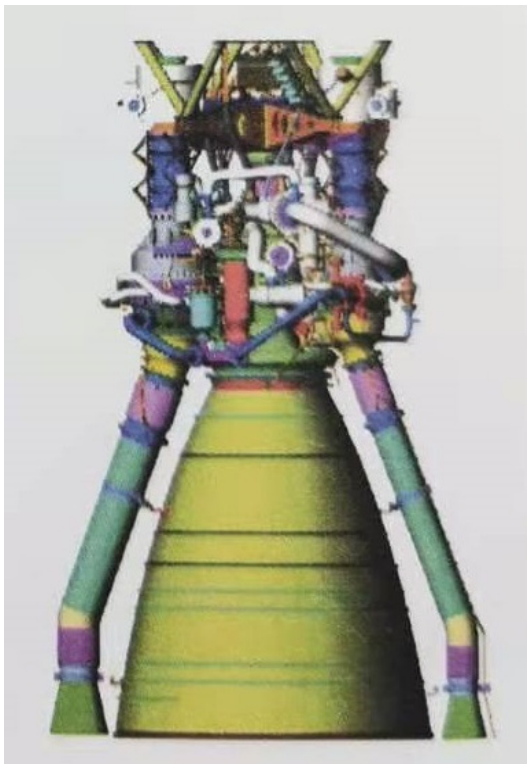

Figure 4: The YF-77 LH2/LOX engine (Chen and Ru 2007, 182). nozzle had the ability of two-way swing; a single rich hydrogen gas generator was adopted, and the gas was arranged in parallel to drive the hydrogen LH2/LOX turbopumps; the thrust chamber had a coaxial DC nozzle; the body of the thrust chambers adopted the method of regenerative cooling, while the nozzle extension part adopted emission cooling; the combustion chambers were ignited by a powder igniter, and the turbopump was driven by a powder starter. During the development, China drew from its previous experience with the LH2/LOX engine and established a 3D digital engine prototype, adopting a large number of digital design methods, including CAD, CFD, FEA, and multi-disciplinary optimization design technology. The overall engine and component technology scheme were optimized, and the number and types of engine tests were reduced, which greatly improved the efficiency of 
engine development and shortened the development period (Chen and Wang 2002). The engine's mixing ratio was 5.5; the thrust chamber pressure was $10.2 \mathrm{MPa}$; the single rocket engine weighed $2750 \mathrm{~kg}$; the nozzle area ratio was 49; the working time was 520 seconds; and the design reliability was 0.999 (Zheng, Wang, and Qiao 2016).

In the process of engine development, from components to the whole unit, from the subsystem to the whole system, a relatively systematic experimental investigation was planned and carried out. The weak links exposed in the experiment were effectively solved, and the inherent reliability of the engine was further improved. The tests carried out included the thrust chamber scale model test, gas generator extrusion test, turbopump system test, theoretical prototype test, engine reliability test, engine reuse test, and engine limit and boundary test. The total number of tests was more than one hundred. The cumulative engine hot-fire test was more than 38,000 seconds; the single engine was started up fifteen times; and the cumulative hot-fire testing time was 5346 seconds ( $\mathrm{Li}$ et al. 2017). Through a series of design and process studies, the overall layout and pipeline design problems of the engine were solved, and the flow resistance loss was reduced. Breakthrough was made in forty-three key technologies in ten categories, including thermal protection technology for high-pressure and high-heatflow thrust chambers and high-performance stable combustion hydrogen/oxygen injector technology. These technical breakthroughs laid a solid foundation for the development of the CZ-5 launch vehicle. On July 2, 2017, the CZ-5 launch vehicle failed on its maiden flight, as the engine flamed out 346 seconds after the rocket took off. The problem was caused by the partial structural fracture of the oxygen turbopump on a YF-77 engine in one of the core stages. After three comprehensive structural reviews, all potential failure points were identified, and the original integral structure was replaced by a separated structure to improve the reliability. Seven engines were tested, and the fault was finally eliminated. On December 27, 2019, the CZ-5Y2 rocket was finally launched successfully, and the YF-77 engine was verified (Chen and Zhao 2020).

It is worth mentioning that although YF-75D adopted in the second stage of CZ-5 was improved and developed on the basis of YF-75, it was the first time that China had adopted an advanced LH2/LOX engine with a closed expansion cycle (also known as a high-pressure staged combustion cycle). The gas auxiliary system was cancelled; the system composition was simplified; the adjustment of the mixing ratio of propellants was made possible; and the second start-up was enabled to improve the inherent reliability. The process of development witnessed the mastery of such key technologies as high-altitude second start-up affected by a vacuum environment; hydrogen turbopumps with long life and high reliability at high speed; heat exchange of the thrust chamber body with high reliability; cold-helium heat exchanger with a small temperature difference; and the design, process, and test technology represented by the powder metallurgy molding technology of small diameter impellers. By the time of the 
first flight of the CZ-5 launch vehicle, the hot-fire test of YF-75D was carried out for more than 45,000 seconds, and its failure-free hot-fire test lasted for more than 30,000 seconds, setting a new record for the development of launch vehicle engines in China. The vacuum specific impulse of YF-75D reached 442 seconds, and some technical parameters reached an internationally advanced level (Figures 5.1-5.3) (Li et al. 2017).

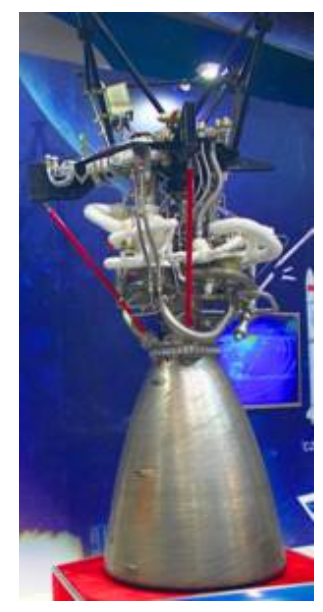

Figure 5.1: The YF75D LH2/LOX engine (Editorial Committee. 2007, 175).

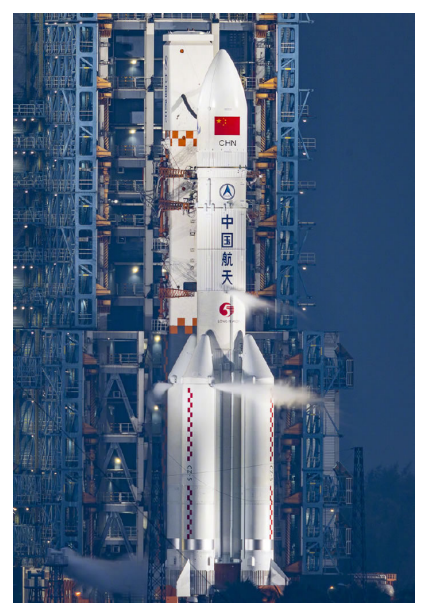

Figure 5.2: The CZ-5 launch vehicle with YF-75D and YF-77 LH2/LOX engines (CLEP 2019).

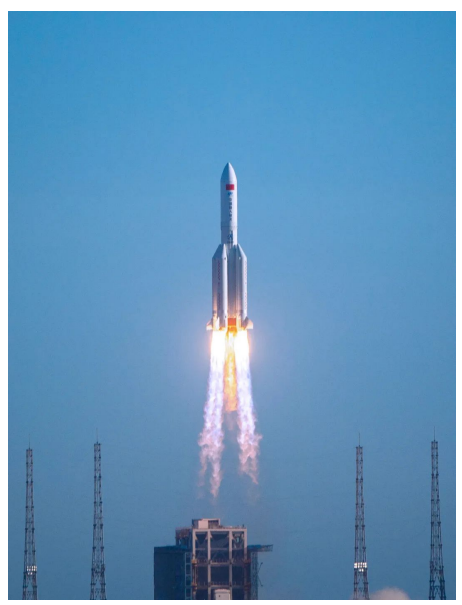

Figure 5.3: The CZ-5B launch vehicle succeeded in the debut flight (CNSA 2020).

In order to complete major space missions, such as a manned lunar landing or deep space exploration, China needs LH2/LOX engines with higher thrust and higher performance. At present, the key technological research on LH2/LOX engines of the new generation with up to 220 tons of thrust is being carried out (Sun and Yue 2019).

\section{Conclusion}

Since the late 1950s, the United States, the Soviet Union, China, Japan, and Europe have engaged in the exploration of LH2/LOX engines. The development of RL-10, the first engine of this type in the United States, started in 1958. It was successfully tested in 1961 and began to serve as the power system for the Centaur upper stage. The D-57 and RD-56 LH2/LOX engines were developed in the early 1960s to be used in the third and fourth stages of the Soviet's N-1 launch vehicle. But N-1 failed in all four launches between 1969 and 1974. The first launch vehicle developed by the ESA, Ariane-1, used an HM-7A LH2/LOX rocket engine in its third stage. The first test launch of the rocket was made on December 24, 1979. Japan's H-2 launch vehicle used an LE-5 LH2/LOX engine in the second stage, whose first successful test launch was on August 12, 1986. Among countries 
to have successfully tested a launch vehicle with LH2/LOX engines, China is the third earliest in the world, following only the United States and the ESA. If a second start-up of the engine is taken into account, China comes in second to the United States.

Completely self-developed, China's LH2/LOX engine is a reflection of complete innovation. At the same time, China's science and space community has accumulated successful experience in the field of LH2/LOX engine development. First, great importance has been attached to the pre-research and theoretical exploration; second, emphasis has been put on the innovation of key technologies; third, a variety of ground tests have been highly valued; fourth, in the process of development and testing, the technical procedure of "Quality Problem Closed Loop" has been extensively adopted to accurately locate faults; fifth, the actual performance of the engine, not an excessive pursuit of advanced technology, has been emphasized; sixth, steady development has been pursued, and the unity of technological continuity and innovation has been valued; seventh, self-reliant technological exploration based on national conditions has been emphasized, while paying close attention to foreign technology trends and taking the lead in the preliminary research; eighth, in terms of project approval, the engine development has been carried out ahead of the launch vehicle, leaving plenty of time for the development of LH2/LOX engines; and ninth, throughout the process of development, attention has been paid to the reliability of design management, while a comprehensive analysis and evaluation of technology, economy, progress, risk management and control, and assurance conditions have been undertaken to form a complete development plan.

\section{Acknowledgments}

The author would like to extend his sincere appreciation to the chief editor Professor Zhang Baichun 张柏春, director of the Institute for the History of Natural Sciences, CAS, Professor Yuri Baturin (Юрий Михайлович Батурин, pilot-cosmonaut of Russia), former director of the Institute for the History of Science and Technology of the Russian Academy of Sciences, and the editor Lü Xin 吕昕.

\section{References}

Bai, Xin 白欣. 2012. “Huaxue liuti lixuejia: Lin Hongsun” 化学流体力学家一一林鸿䔉 [Chemical Fluid Dynamist: Lin Hongsun]. Lixue yu shijian 力学与实践 [Mechanics in Engineering] (6): 78-84. CASC. 2010. “Tanfang Chang'e Erhao tanyue weixing yanzhi guocheng [zutu]” 探访嫦娥二号探 月卫星研制过程[组图] [Explore the Development of Chang'e-2 Lunar Probe (Photos)]. Last modified September 30, 2010. http://news.eastday.com/c/20100930/u1a5473367.html.

Chen, Jun 尘军, and Wang Heng 王桁. 2002. “Xitong dongtai fangzhen jishu zai gaoya buran qingyang fadongii yanzhi zhong de yingyong” 系统动态仿真技术在高压补燃氢氧发动机研制 中的应用 [The Application of System Dynamic Simulation Technology to the Development of 
LH2/LOX Staged Combustion Rocket Engine]. Daodan yu hangtian yuzai jishu 导弹与航天运载 技术 [Missiles and Space Vehicles] (5): 29-35.

Chen, Li 陈立, and Zhao Cong 赵聪. 2020. “Changwu YF-77, ruhe zouchu zhi'an shike?” 长五 YF-77, 如何走出至暗时刻? [YF-77 of CZ-5, How to Get Out of the Dark Time?]. Taikong tansuo 太空探索 [Space Exploration] (1): 16-19.

Chen, Minkang 陈闽慷, and Ru Jiaxin 茹家欣. 2007. Shenjian lingxiao: Changzheng xilie huojian de fazhan licheng 神箭凌霄: 长征系列火箭的发展历程 [Arrows Soaring into Space: The Development of the CZ Rockets]. Shanghai: Shanghai Science and Technology Education Press. CLEP, CNSA. 2019. “Changzheng Wuhao yunzai huojian 'xin' kandian” 长征五号运载火箭 “新” 看点 [“New” Highlights of the CZ-5 Launch Vehicle]. Last modified December 31, 2019. www.sastind.gov.cn/n112/n117/c6808565/content.html.

CNSA. 2020. “Changzheng Wuhao B yunzai huojian shoufei chenggong” 长征五号 B 运载火箭首 飞成功 [The CZ-5B Launch Vehicle Succeeded in the Debut Flight]. Last modified May 6, 2020. http://www. cnsa.gov.cn/n6758823/n6758838/c6809491/content.html.

Editorial Committee. 1996. Shijie hangtian yunzaiqi daquan 世界航天运载器大全 [A Complete Collection of the World's Space Launch Vehicles]. Beijing: China Aeronautic Publishing House.

Editorial Committee. 2007. Shijie hangtian yunzaiqi daquan 世界航天运载器大全 [A Complete Collection of the World's Space Launch Vehicles]. Beijing: China Aeronautic Publishing House.

Fan, Hongye 㚞洪业, ed. 1999. Zhonguo Kexueyuan biannianshi: 1949-1999 中国科学院编年史: 1949 1999 [Annals of the Chinese Academy of Sciences: 1949-1999]. Shanghai: Shanghai Science and Technology Education Press.

Hong, Youshi 洪友士. 2006. “Zai meiyou lu de difang qiusuo he pandeng: Zhongguo Kexueyuan Lixue Yanjiusuo wushinian" 在没有路的地方求索和攀登一一中国科学院力学研究所五十年 [Seeking and Climbing Where There is No Road: Fifty Years of the Institute of Mechanics, Chinese Academy of Sciences]. Kexue xinwen 科学新闻 [Science News] (1): 4-6.

Jia, Daling 贾大玲, and Jin Zhiqiang 金志强. 2019. “'Changzheng' Sanhao Jia xilie yunzai huojian fazhan lishi yu chengjiu” “长征”三号甲系列火箭发展历史与成就 [Development History and Achievements of CZ-3A Rocket Series]. Hangtian gongye guanli 航天工业管理 [Aerospace Industry Management] (10): 47-52.

Li, Chengzhi 李成智. 2006. Zhongguo hangtian jishu fazhan shigao (zhong) 中国航天技术发展史稿 (中) [A Draft History of Space Technology in China (vol. 2)]. Jinan: Shandong Education Press.

Ли, Чэнчжи [Li Chengzhi]. 2014. Развитие китайских космических технологий. Под ред. Бао Оу, Хан Ихуа, Ю. М. Батурина. СПб.: Нестор-История.

Li, Dong 李东, Wang Jue 王珏, He Wei 何嵬, Li Pingqi 李平岐, and Mou Yu 牟宇. 2017. “Changzheng Wuhao yunzai huojian zongti fang'an ji guanjian jishu” 长征五号运载火箭总体 方案及关键技术 [General Scheme and Key Technologies of CZ-5 Launch Vehicle]. Daodan yu hangtian yuzai jishu (3): 1-5, 113.

Li, Yufei 李宇飞. 2019. “Kuayue baifa daguan de Changzheng Sanhao Jia xilie yunzai huojian” 跨越百发大关的长征三号甲系列运载火箭 [The 100th Launch of CZ-3A Rocket Series]. Taikong tansuo (5): 16-19.

Long, Lehao 龙乐豪, ed. 2007. Shijie hangtian yunzaiqi daquan 世界航天运载器大全 [A Complete Collection of the World's Space Launch Vehicles]. Beijing: China Aeronautic Publishing House. 
Long, Lehao, and Nan Yan 南燕. 2007. “Changzheng Sanhao Jia xilie huojian yanzhi huigu” “长征”三号甲系列火箭研制回顾 [Review of the Development of CZ-3A Rocket Series]. Hangtian gongye guanli (6): 14-17.

Qiu, Chenhui 邱晨辉. 2016. “Changzheng Wuhao fadongji shi zenyang liancheng de: Jiemi Zhongguo zuida huojian de 'xinzang'” 长征五号发动机是怎样炼成的一一揭秘中国最大火箭的 “心脏” [How CZ-5 Engine was Made: Uncover the “Heart” of China's Largest Rocket]. Chuangxin shidai 创新时代 [Innovation Time] (12): 33-35.

Sun, Jiguo 孙纪国, and Yue Wenlong 岳文龙. 2019. “Woguo datuili buran qingyang fadongji yanjiu jinzhan” 我国大推力补燃氢氧发动机研究进展 [Advances of Large-Thrust Staged Combustion Cycle LH2/LOX Rocket Engine in China]. Shanghai hangtian 上海航天 [Aerospace Shanghai] 36 (6): 19-23, 68.

Wang, Heng. 1993. “YF-75 fadongji de sheji tedian ji jinzhan qingkuang” YF-75 发动机的设计特点 及进展情况 [Design Features and Development of the YF-75 Engine]. Daodan yu hangtian yuzai jishu (4): 72 .

Wang, Weibin, Zheng Dayong, and Qiao Guiyu. 2013. "Development Status of the Cryogenic Oxygen/Hydrogen YF-77 Engine for Long-March 5." 64rd International Astronautical Congress, Beijing, China. International Astronautical Federation. IAC-13-C4.1. 2013-09-23.

Wang, Zhiren 王之任. 1999. “Qingyang fadongji yanzhi de qishige zhouye” 氢氧发动机研制的七 十个昼夜 [Seventy Days and Nights of the Development of LH2/LOX Engines]. In Zhongguo hangtian tengfei zhilu 中国航天腾飞之路 [Achievement of China's Space Industry], edited by Wang Liheng 王礼恒. Beijing: Chinese Literature and History Press.

Xiao, Rong 肖嵘. 1999. Tianlu: Zhuming hangtian zhuanjia Ren Xinmin 天路一一著名航天专家任新 民 [The Road to Loftiness: Famous Space Expert Ren Xinmin]. Beijing: PLA Press.

Yuan, Yaozhang 袁耀章. 1998. “Changzheng Sanhao Jia yunzai huojian sanji qingyang fadongji xitong” 长征三号甲运载火箭三级氢氧发动机系统 [LH2/LOX Engine System for the Third Stage of CZ-3A Launch Vehicle]. Diwen gongcheng 低温工程 [Cryogenics] (2): 18-21.

Zhang, Jinfu 张劲夫. 2006. “Zhongguo diyike renzaoweixing shi zenyang shangtian de?” 中国第 一颗人造卫星是怎样上天的? [How did China's First Artificial Satellite be Launched into Space]. Last modified October 17, 2006. www.chinanews.com/other/news/2006/1017/805368.shtml.

Zhang, Jun 张钧, ed. 1986. Dangdai Zhongguo de hangtian shiye 当代中国的航天事业 [Space Industry in Contemporary China]. Beijing: China Social Sciences Press.

Zhang, Nan. 2013. "The Development of LOX/LH2 Engine in China." 64rd International Astronautical Congress, Beijing, China, September 23, 2013. International Astronautical Federation. IAC-13-C4.1:5.

Zhang, Yong 张勇, Li Zhengyu 李正宇, Li Qiang 李强, Hu Zhongjun 胡忠军, and Li Qing 李青. 2007. “Diwen yeti chuxiang jiaya paiye guocheng jisuan moxing bijiao” 低温液体储箱加压排液 过程计算模型比较 [Comparison of Numerical Model for Pressurization of Cryogenic Liquid Tank]. Diwen gongcheng (2): 24-27, 39.

Zheng, Dayong 郑大勇, Tao Ruifeng 陶瑞峰, Zhang Xi 张胥, and Xiang Meng 向猛. 2014. “Datuili qingyang fadongji guanjian jishu ji jiejue tujing” 大推力氢氧发动机关键技术及解决途 径 [Key Technologies and Solutions for High-Thrust LH2/LOX Rocket Engines]. Huojian tuijin 
火箭推进 [Journal of Rocket Propulsion] 40 (2): 22-27, 35.

Zheng, Dayong, Wang Weibin 王维涁, and Qiao Guiyu 乔桂玉. 2016. “Xinyidai yunzaihuojian 50 dun ji qingyang fadongji yanzhi jinzhan” 新一代运载火箭 50 吨级氢氧发动机研制进展 [Progress of the 50-Ton Class Oxygen/Hydrogen Engine for New Generation Launch Vehicle]. Daodan yu hangtian yuzai jishu (5): 11-15, 22.

Zhu, Senyuan 朱森元, and Zhu Yaoquan 朱尧铨. 1999. “Qingyang fadongji de dansheng” 氢氧 发动机的诞生 [The Birth of LH2/LOX Engines]. In Zhongguo hangtian tengfei zhilu, edited by Wang Liheng. Beijing: Chinese Literature and History Press. 